\title{
Metabolic Studies of a Family with Massive Formiminoglutamic Aciduria
}

\author{
THOMAS L. PERRY, ${ }^{(35)}$ DEREK A. APPLEGARTH, MARION E. EVANS, AND \\ SHIRLEY HANSEN \\ Departments of Pharmacology and Paediatrics, University of British Columbia, Vancouver, \\ British Columbia, \\ Canada
}

EGIL JELLUM

Institutt for Klinisk Biokjemi, Rikshospitalet, Oslo, Norway

\section{Extract}

We have described two siblings who excrete massive amounts (up to $3.89 \mathrm{mmol} / 24 \mathrm{hr}$ ) of $N$-formiminoglutamic acid (FIGLU) in their urine. This unusual compound was isolated from urine, purified, and firmly identified as FIGLU by combined gas chromatography-mass spectrometry. The patients presumably have a deficiency in activity of the hepatic enzyme, glutamate formiminotransferase, which carries out the fourth sequential step in the main pathway of histidine degradation. Unlike children reported previously with this disorder, our patients had normal serum folate levels, had no hematologic abnormalities, and were not mentally retarded. Very small amounts of FIGLU were present in the plasma of one of the patients, but FIGLU was not detectable in the cerebrospinal fluid of either patient. Administration of pharmacologic doses of folic or folinic acid produced a decrease in excretion of FIGLU in urine. Histidine loading caused a small and comparable urinary excretion of FIGLU in the children's parents and in control adult subjects.

\section{Speculation}

Glutamate formiminotransferase deficiency may represent a further example of a genetically determined metabolic error which does not result either in accumulation of a toxic metabolite or in failure to synthesize a crucial metabolite, and which therefore produces no clinical disease syndrome.

Human urine normally contains only very small amounts of FIGLU, a metabolite in the major degradative pathway of histidine. Healthy adults excrete about $8 \mu \mathrm{mol} / 24 \mathrm{hr}(22)$. Larger amounts of FIGLU are excreted by some patients with folic acid or vitamin $\mathrm{B}_{12}$ deficiencies, and quantitation of urinary FIGLU after oral histidine loading has been used as a test for deficiencies of folate or vitamin $B_{12}(7,10,23)$. In addition, a few patients have been encountered who excreted abnormally large quantities of FIGLU in their urine without showing any evidence of folate or vitamin $B_{12}$ deficiency. In these patients, the excessive urinary FIGLU was attributed to deficiency or absence of activity of the hepatic enzyme glutamate formiminotransferase (EC. 2.1.2.5) (19).

Arakawa and his coworkers have described five Japanese patients (four of them infants) with glutamate formiminotransferase deficiency $(1-6)$. The patients were all mentally retarded, and had abnormal electroencephalograms (EEGs) and pneumoencephalographic evidence of cortical atrophy and ventricular dilatation. Serum folate values were normal or elevated in all five patients, but two of the patients had changes in peripheral blood or bone marrow suggestive of a functional folate deficiency. The diagnosis was proven in each of the five Japanese patients by the finding of markedly deficient enzyme activity for glutamate formiminotransferase in specimens of liver obtained at biopsy or autopsy. A sixth case of glutamate formiminotransferase deficiency has been described by Herman and coworkers (9) in a Caucasian woman of normal intelligence, whose symptoms included weight loss and intolerance of dietary carbohydrate, and whose bone marrow showed megaloblastic changes despite a normal serum folate level.

We describe here two further cases of probable glutamate formiminotransferase deficiency occurring in a Caucasian sibship. These children excrete massive amounts of FIGLU in their urine, but they have normal serum and erythrocy te folate levels, and no hematologic abnormalities. Although they have mild cerebral dysfunction, they show no evidence of mental or physical retardation that can be attributed to their enzymatic defect.

\section{PATIENTS}

The proband of this study, patient $K S$, was first investigated at the age of $23 / 4$ years because of delayed speech development. Two-dimensional paper chromatography of his urine for amino acids revealed a grossly excessive amount of glutamic acid (Fig. 1). However, when the urine was analyzed by automated column chromatography, it did not contain abnormal amounts of glutamic acid, but instead contained an unusual compound which was subsequently identified as FIGLU.

At $3 \frac{1}{4}$ years, $K S$ was $1 \mathrm{SD}$ below the mean in height and weight, while his head circumference was 1 SD above the mean. He exhibited general hypotonia, was clumsy, had a wide-based gait, and ran awkwardly. Otherwise there were no neurologic abnormalities. He had only 12 word-sounds. An EEG was normal, and audiometric testing was unremarkable. Psychologic examination indicated an I.Q. of 100 on the Stanford-Binet test, with considerable scatter. On the Peabody Picture Vocabulary Test, receptive vocabulary was at the level of $2 \frac{1}{4}$ years. Because $K S$ continued to excrete large amounts of FIGLU in his urine, the remaining family members were studied clinically and biochemically.

$L S$, an older sister aged 8 years, had enjoyed good health 


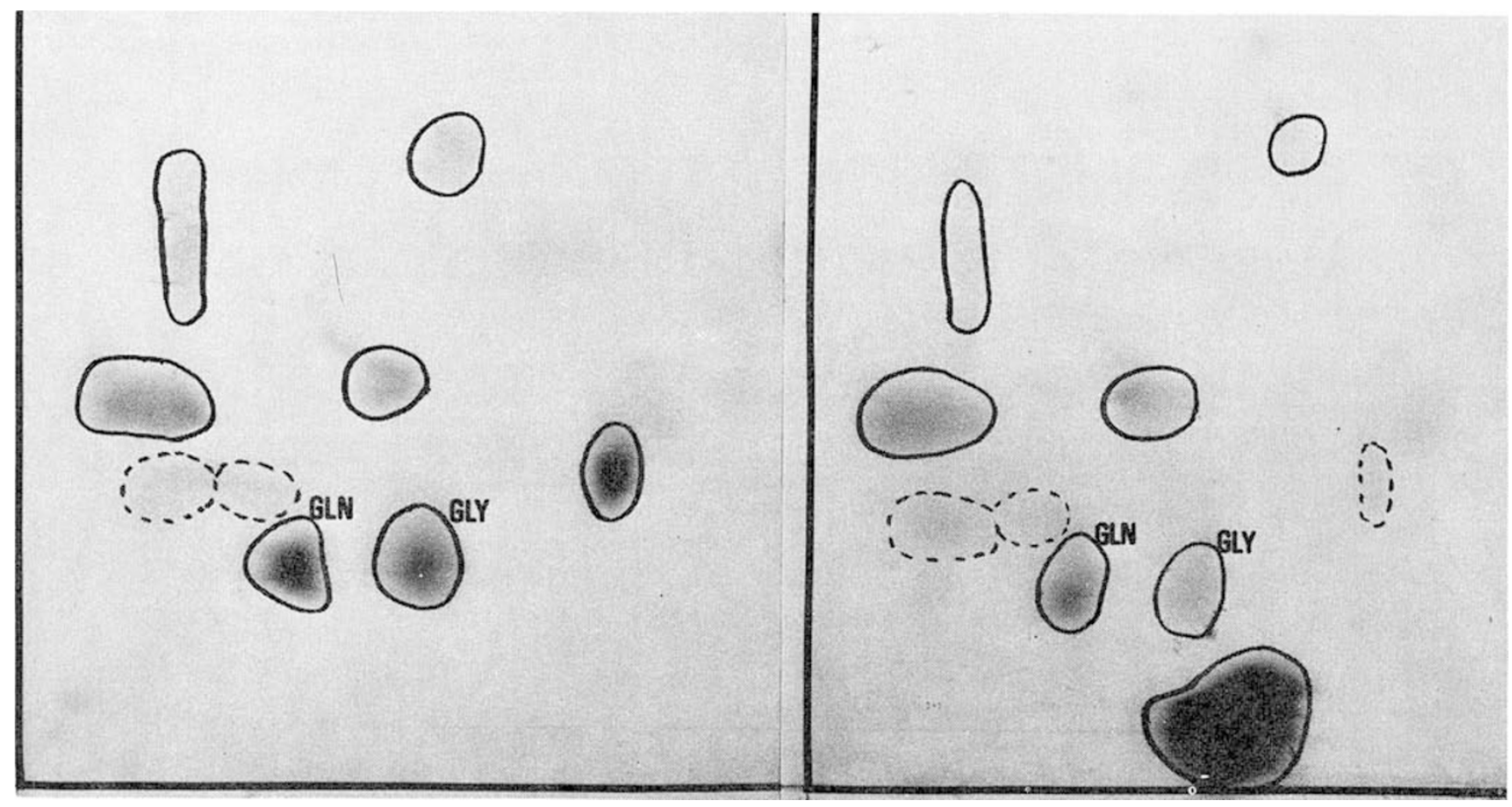

Fig. 1. Two-dimensional paper chromatograms of amino acids in urine of normal child (left) and patient KS (right). A 25 - $\mu$ g creatinine equivalent of urine was applied to each chromatogram. The large spot below and to the right of glycine is glutamic acid.

and developed normally, except that she only began to use single words at $2-2 \frac{1}{2}$ years. She too was found to excrete FIGLU in large quantities. Her height and weight were normal, and her head circumference was 1 SD above the mean. Detailed examination revealed normal hearing, but she had a refractive error and right-sided amblyopia. She had no right-left distinction as yet, and was hypotonic and clumsy. Although she had no history of seizures, her EEG was diffusely abnormal and suggestive of a disturbance of cerebral function of subcortical origin. $L S$ had proved somewhat slow in school, only completing grade 1 work in her second school year. Psychological testing showed a full-scale score of 95 on the Wechsler Intelligence Scale for Children, but with considerable scatter. A battery of additional psychometric tests indicated some delay in reading ability and in visual reception, visual association, and auditory and visual memory.

$K a S$, a younger sister of the proband, was found not to excrete FIGLU. At the age of 18 months, her height and weight were normal, but her head circumference of $42 \mathrm{~cm}$ was more than 3 SD below the mean. She had alternating esotropia so marked that neither eye could be abducted much beyond the midline, but no other abnormalities of the nervous system were noted. Assessment of her behavioral development by the Gesell technique showed that she had mastered nearly all of the 15 months' items, but at her own age level of 18 months, she passed only 8 out of 13 items.

The children's parents were both in good physical and mental health, and were not consanguineous. The father was of German origin, and the mother of English origin. A sister of the children's mother was profoundly mentally retarded. Neither the parents nor this retarded maternal aunt were FIGLU excretors.

\section{METHODS}

\section{ANALYTICAL PROCEDURES}

1. Urine samples were chromatographed two-dimensionally on Whatman no. 1 chromatography paper, using pyridine-acetone- $\mathrm{NH}_{4} \mathrm{OH}$-water $(45: 30: 5: 20, \mathrm{v} / \mathrm{v})$ as the first solvent, and isopropanol-formic acid-water $(75: 12.5: 12.5, \mathrm{v} / \mathrm{v})$ as the second solvent (13). The amino acids on the sheets were visualized by spraying them with ninhydrin-lutidine in ethanol (15).

2. Amino acids were identified and quantitated in specimens of plasma, cerebrospinal fluid (CSF), and urine on a Technicon amino acid analyzer (24), using the single column lithium citrate buffer elution system of Perry et al. (16).

3. FIGLU was measured in CSF, plasma, and urine on the amino acid analyzer when present in low concentrations. When FIGLU was present in urine in high concentrations, it was measured by the colorimetric method of Tabor and Wyngarden (18), which utilizes the alkaline ferricyanide-nitroprusside reaction. Authentic FIGLU, as the hemibarium salt (25), was used for constructing standard curves for the colorimetric assay, and also for determining ninhydrin color yield relative to that of a norleucine internal standard on the amino acid analyzer. Several urine specimens were assayed by both the colorimetric method and with the amino acid analyzer. The former method was found to give reliable measurements of urinary FIGLU, when urine specimens contained as little as 1 $\mu \mathrm{mol} / \mathrm{ml}$.

4. Folate in serum and erythrocytes $(17,21)$ and vitamin $B_{12}$ in serum (20) were measured by standard radioassay techniques.

\section{ISOLATION OF UNKNOWN URINARY COMPOUND}

Urine samples of patient $K S$ contained an unknown ninhydrin-negative compound which decomposed rapidly to glutamic acid at high $\mathrm{pH}$. The compound could be visualized readily on paper chromatograms, if the latter were exposed to ammonia vapor before being sprayed with ninhydrin. A volume of the patient's urine containing about $5 \mathrm{mg}$ creatinine was chromatographed one-dimensionally on Whatman no. 3MM paper in isopropanol-formic acid-water $(75: 12.5: 12.5$, $\mathrm{v} / \mathrm{v}$ ). Small strips of the chromatogram were exposed to ammonia vapor, and then sprayed with ninhydrin, revealing a heavy ninhydrin-positive band between $R_{F} 0.51$ and 0.68 . This region of the remaining unsprayed chromatogram was then eluted with water, and the eluate was lyophilized and dissolved in a small volume of water. The latter was applied in a band to another sheet of Whatman no. $3 \mathrm{MM}$ paper. This was then subjected to high voltage electrophoresis in a Gilson Varsol- 
cooled tank type electrophoresis apparatus (26) in pyridine acetate buffer, $\mathrm{pH} 4.3$, at $2.5 \mathrm{kV}$ for $2 \mathrm{hr}$. Ninhydrin spray, after prior exposure of the paper to ammonia vapor, showed that the unknown compound had migrated toward the anode as a band for $6-9 \mathrm{~cm}$ from the line of application, and that it was well separated from all remaining urinary amino acids. The compound was eluted from the electrophoresis paper with water, and the eluate was lyophilized. The dry residue was dissolved in $5 \mathrm{ml}$ methanol, to which $25 \mathrm{ml}$ anhydrous diethyl ether were then added. Crystals which appeared after the solution stood at $-20^{\circ}$ overnight were separated by filtration, and were dried over $\mathrm{KOH}$ and $\mathrm{P}_{2} \mathrm{O}_{5}$ in a vacuum desiccator. The final yield of the purified unknown compound was about $1 \mathrm{mg}$.

GAS CHROMATOGRAPHIC-MASS SPECTROMETRIC IDENTIFICATION OF URINARY COMPOUND

The isolated urinary compound, as well as authentic FIGLU (25), were each examined by combined gas chromatographymass spectrometry using a Varian type $\mathrm{CH} 7$ instrument (27). The apparatus consisted of a Varian 1400 gas chromatograph, a molecular separator of the glass frit type (kept at $230^{\circ}$ ), and a single-focusing mass spectrometer operated at $70 \mathrm{eV}$. The gas chromatography column $(2.5 \mathrm{~m}$ by $0.625 \mathrm{~cm}$ O.D.) was filled with $10 \%$ OV-17 on Gas Chrom Q, 80/100 mesh (28).

Authentic FIGLU (hemibarium salt) (25) was dissolved in $0.001 \mathrm{~N} \mathrm{HCl}$ and stored as a stock solution at $-20^{\circ}$. An aliquot containing about $0.1 \mathrm{mg}$ FIGLU was pipetted into a stoppered tube, and the water was removed under a stream of nitrogen. To the dry residue was added $0.5 \mathrm{ml}$ of a mixture of methanol and thionyl chloride (29). The methanol-thionyl chloride reagent was prepared by the careful addition of $1 \mathrm{ml}$ thionyl chloride to $10 \mathrm{ml}$ methanol precooled to $-77^{\circ}$ with Dry Ice. The solution of FIGLU in methanol-thionyl chloride was heated to $45^{\circ}$ for $15 \mathrm{~min}$ after which the excess of the methanol-thionyl chloride reagent was removed under a stream of nitrogen. To the methyl-esterified residue were added 0.1 $\mathrm{ml}$ dichloromethane $(29)$ and $0.1 \mathrm{ml}$ trifluoroacetic anhydride (29). The mixture was kept at $80^{\circ}$ for exactly $5 \mathrm{~min}$, then immediately injected into the gas chromatograph-mass spectrometer. Since the derivatized FIGLU decomposed rapidly at room temperature, it was necessary to store it at $-77^{\circ}$ if repeated injections were required.

The unknown compound isolated from urine was derivatized, and then injected into the gas chromatograph-mass spectrometer, in exactly the same manner as described for authentic FIGLU.

\section{HISTIDINE LOADING TESTS}

Histidine loading tests were performed on the parents of $K S$ and $L S$, as well as on three control adult subjects. Each subject consumed $0.1 \mathrm{~g} / \mathrm{kg}(0.048 \mathrm{mmole} / \mathrm{kg})$ of L-histidine hydrochloride monohydrate (30) after an overnight fast. Venous blood was obtained for determination of plasma amino acids at $0,1,2$, and $4 \mathrm{hr}$; urine was collected from 0 to $2 \mathrm{hr}, 2$ to 4 $\mathrm{hr}$, and 4 to $8 \mathrm{hr}$ for FIGLU determination.

\section{RESULTS}

\section{IDENTIFICATION OF URINARY COMPOUND AS FIGLU}

Every urine specimen of patients $K S$ and $L S$ that was chromatographed two-dimensionally on paper for amino acids showed a very large spot of what at first appeared to be glutamic acid (Fig. 1). Because urine specimens were frozen immediately after collection, and because the chromatograms showed that urines contained normal amounts of glutamine, the glutamic acid could not have been an artifact caused by hydrolysis of glutamine. Neither child was receiving any drugs, thus ruling out the possiblility that the urines contained a ninhydrin-positive drug metabolite which happened to cochromatograph with glutamic acid. When urine specimens from the patients were chromatographed on the amino acid analyzer, it became apparent that they contained only trace amounts of glutamic acid, but did contain large amounts of an unknown compound. This compound was eluted in the system we used (16) as a broad peak appearing between $\alpha$-amino- $n$-butyric acid and valine. On a Beckman 120C amino acid analyzer (31), using sodium citrate elution buffers, the unknown compound emerged as a broad peak between cystine and methionine.

We concluded that the unknown compound itself was ninhydrin-negative, and therefore not seen when urines were chromatographed on paper in acidic solvents, it nevertheless yielded a ninhydrin-positive product when chromatographed on the amino acid analyzer. Presumably, the compound was, like urea, decomposed as the column effluent passed through the $95^{\circ}$ heating coil before the colorimeters.

When the unknown compound was isolated and purified from urine, it was found that both it and authentic FIGLU were rapidly decomposed to glutamic acid when exposed to ammonia. The purified urinary compound and authentic FIGLU were eluted identically from the columns of the amino acid analyzer, emerging as a broad peak 10-12 min before valine. The urinary compound and authentic FIGLU migrated identically toward the anode during high voltage paper electrophoresis in pyridine acetate buffer, pH 4.3. When chromatographed on paper in four different acidic solvents, the urinary compound showed $R_{F}$ values close to, but not identical with, those of authentic FIGLU. The latter compound migrated at a slightly different rate because it was available only as the hemibarium salt.

Precise identification of the purified compound isolated from the patient's urine was accomplished by one of us $(E J)$, using gas chromatography-mass spectrometry. The derivatized urinary compound and derivatized FIGLU $(N, N$-di-trifluoroacetyl formiminoglutamic acid dimethyl ester) both showed a single dominant peak on gas chromatograms with an identical retention time (Fig. 2). Furthermore, the mass spectrum of the derivatized urinary compound was completely identical with the mass spectrum of derivatized authenic FIGLU (Fig. 3). These data prove that the urinary compound was indeed FIGLU.

\section{FIGLU IN PHYSIOLOGIC FLUIDS}

Random urine specimens from patient $K S$ contained FIGLU in concentrations ranging from $9.6-25.7 \mu \mathrm{mol} / \mathrm{mg}$ of creatinine. Two accurate 24 -hr urine collections from this child showed that he excreted 3,890 and $3,486 \mu \mathrm{mol}$ of FIGLU/24 $\mathrm{hr}(678$ and $608 \mathrm{mg} / 24 \mathrm{hr}$ ). His sister, $L S$ excreted 2,834 $\mu \mathrm{mol} / 24 \mathrm{hr}(493 \mathrm{mg} / 24 \mathrm{hr}$ ). Fasting plasma obtained from patient $K S$ on two different occasions contained small amounts of FIGLU $(4.5$ and $4.4 \mu \mathrm{mol} / 100 \mathrm{ml})$. No FIGLU was detectable in the plasma of patient LS, either when she was fasting, or $2 \mathrm{hr}$ after a large protein-containing meal. FIGLU could not be detected in the CSF of either child. All other amino acids were entirely normal in the fasting plasma and CSF of both children. In particular, there was no elevation of histidine concentrations, and no diminution of glutamic acid or methionine concentrations. Neither were excessive amounts of histidine, nor metabolic intermediates between histidine and FIGLU, found in the urine of the children.

\section{FOLATE LEVELS AND HEMATOLOGIC FINDINGS}

In patient $K S$ the serum folate level was $7.0 \mathrm{ng} / \mathrm{ml}$ (normal $3-16$ ), the erythrocyte folate was $418 \mathrm{ng} / \mathrm{ml}$ (normal $>200$ ), and the serum vitamin $B_{12}$ level was $771 \mathrm{pg} / \mathrm{ml}$ (normal 150-800). For patient $L S$, the three corresponding values were $4.7 \mathrm{ng} / \mathrm{ml}, 295 \mathrm{ng} / \mathrm{ml}$, and $560 \mathrm{pg} / \mathrm{ml}$. Hemoglobin levels, erythrocyte morphology, leucocyte differential counts, and 
platelets were entirely normal in the peripheral blood of both children. In view of these normal findings, neither child was subjected to bone marrow puncture. However, in view of the absence of abnormalities in peripheral blood, and in view of normal values for serum iron and iron-binding capacity determined in patient $L S$, it is reasonable to conclude that the the bone marrows of the children were normal.

\section{FIGLU EXCRETION AFTER FOLATE ADMINISTRATION}

Figure 4 illustrates the major degradative metabolic pathway for histidine in man, and shows how tetrahydrofolic acid is required as the acceptor for the formimino group which is transferred from FIGLU in the enzymatic reaction which yields glutamic acid and $N^{5}$-formiminotetrahydrofolic acid. We, therefore, attempted to explore the possible effect on urinary FIGLU excretion of administering pharmacologic doses of folates to our patients. $K S$ (weight $13 \mathrm{~kg}$ ) was given 5 $\mathrm{mg}$ folic acid by mouth every $8 \mathrm{hr}$ for 3 days. $L S$ (weight 23 $\mathrm{kg}$ ) was given $6 \mathrm{mg}$ folinic acid $\left(N^{5}\right.$-formyltetrahydrofolic acid) by intramuscular injection every $8 \mathrm{hr}$ for 3 days. Twenty-four-hour collections of urine were made for 2 consecutive days before folate administration, during the second and third days of folate therapy, and for the first 2 days after folate therapy was discontinued.

Table 1 shows FIGLU excretion in urine for both patients before and after folate therapy. The results suggest that both folic acid and folinic acid, when given in massive doses, reduced the urinary excretion of FIGLU. This effect indicates that glutamate formiminotransferase enzyme activity was not entirely absent in the livers of the patients. If their enzyme had an abnormally high $\mathrm{K}_{\mathrm{m}}$ for the substrate, tetrahydrofolate, increasing concentrations of the latter might be expected to increase enzyme activity and thus to decrease FIGLU excretion. Unfortunately, some of the 24-hr urine collections were clearly not complete, and are indicated by

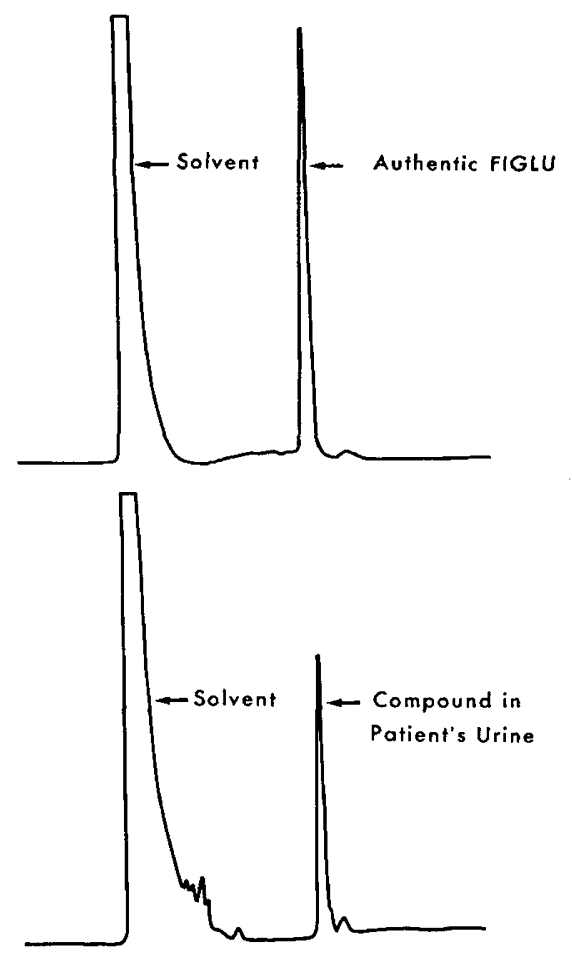

Fig. 2. Gas chromatograms of derivatized authentic $N$-formiminoglutamic acid (FIGLU) (above) and of the purified urinary compound (below). $N$-Formiminoglutamic acid was converted to $N, N$-di-trifluoroacetyl formiminoglutamic acid dimethyl ester before injection into the gas chromatograph.
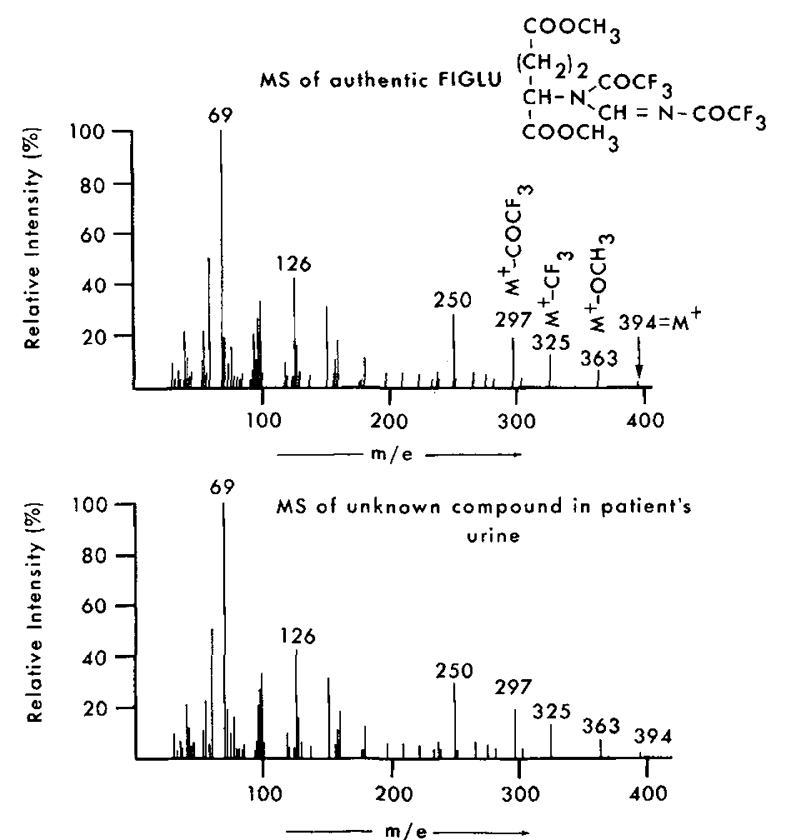

Fig. 3. Mass spectra $(M S)$ of derivatized authentic $N^{T}$-formiminoglutamic acid (FIGLU) (above) and of the purified urinary compound (below).

footnote 2. The figures for the total 24-hr FIGLU excretion may in several instances be underestimated. However, in relation to creatinine excretion, urinary FIGLU was reduced markedly in both patients by folate therapy.

\section{FIGLU EXCRETION BY PARENTS AFTER HISTIDINE LOADING}

The parents of the affected children and three control adult subjects were given an oral histidine loading test. The histidine load $(0.048 \mathrm{mmol} / \mathrm{kg})$ caused a 7 - to 11 -fold rise in the plasma histidine concentration at $1 \mathrm{hr}$, with a fall by $4 \mathrm{hr}$ to about twice the fasting histidine concentration. Two-dimensional paper chromatograpy of the urine specimens of all five subjects indicated that small amounts of FIGLU were excreted in the first $4 \mathrm{hr}$ after the histidine load, and trace amounts were excreted between 4 and $8 \mathrm{hr}$. The levels of FIGLU in urine were too low for accurate measurement by the colorimetric method used, and therefore, were determined on the amino acid analyzer. Table 2 shows the amounts of FIGLU excreted in $8 \mathrm{hr}$ after histidine loading by the children's parents and by the control subjects. It is apparent that these two obligate heterozygotes for glutamate formiminotransferase deficiency did not excrete more FIGLU in their urine than did normal adults.

\section{DISCUSSION}

The two siblings described here probably have true glutamate formiminotransferase deficiency, because they displayed no evidence of folate or vitamin $B_{12}$ deficiency, and because they were taking no drugs which might have interfered with folate metabolism. They differ from four of the Japanese infants with glutamate formiminotransferase deficiency described previously $(2-5)$ in that their serum folate levels were normal rather than elevated. They differ from three of the six cases of this disorder reported previously $(3,4,9)$ in that they had no evidence of hematologic disturbance.

The daily excretion of FIGLU in urine by our patients was much greater in proportion to their body weight than that reported for most of the six previously studied cases. Only in the second patient reported by Arakawa et al. (3) did spontaneous urinary FIGLU excretion, without prior histidine 


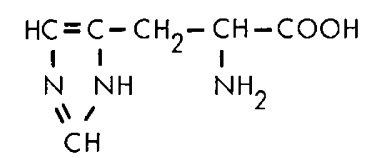

HISTIDINE

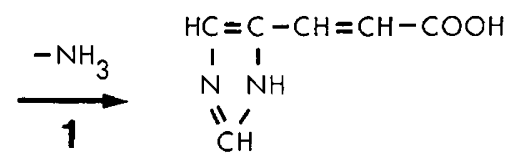

UROCANIC ACID

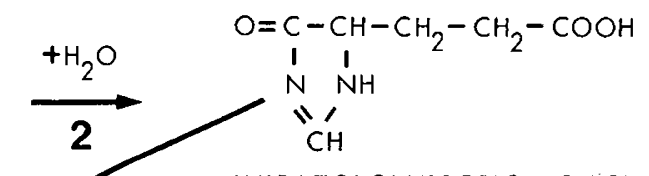

IMIDAZOLONEPROPIONIC ACID
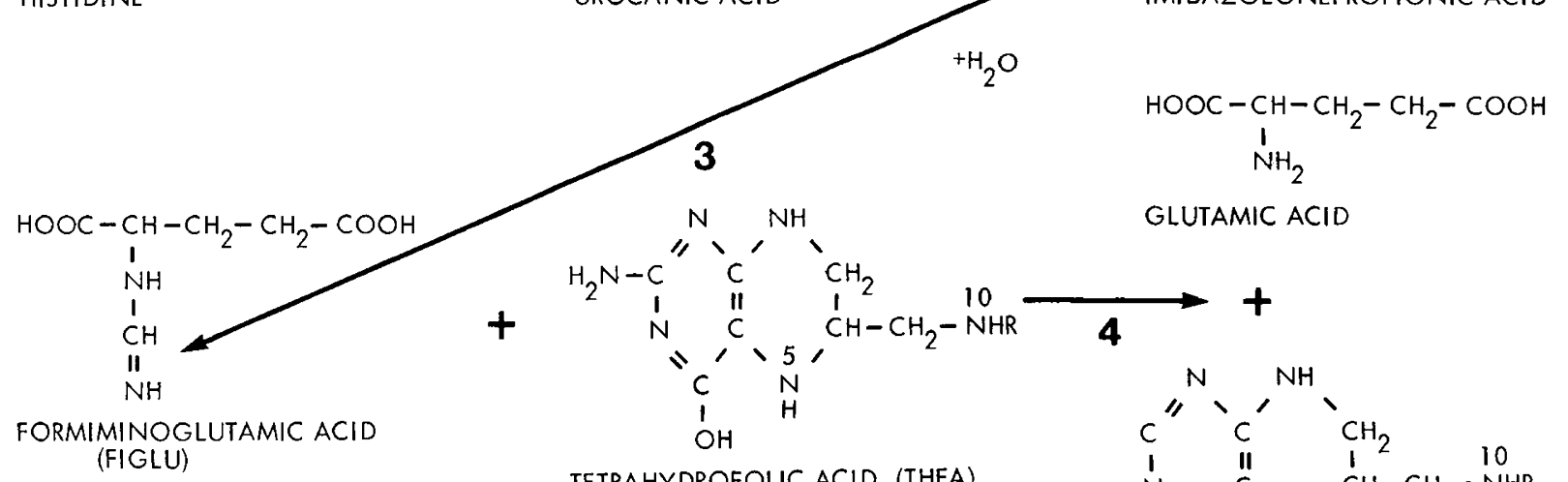

TETRAHYDROFOLIC ACID (THFA)

1. HISTIDASE

2. UROCANASE

3. IMIDAZOLONEPROPIONASE

4. GLUTAMATE FORMIMINOTRANSFERASE<smiles></smiles>

$\mathrm{C}-\mathrm{N}-\mathrm{CH}-\mathrm{CH}_{2}-\mathrm{CH}_{2}-\mathrm{COOH}$
II I I I
O $\mathrm{H} \mathrm{COOH}$

Fig. 4. Diagram showing the chemical steps and enzymes involved in the degradation of histidine to glutamic acid.

Table 1. Effect of folate administration on $N$ formiminoglutamic acid (FIGLU) excretion in urine

\begin{tabular}{|c|c|c|c|}
\hline \multirow[b]{2}{*}{ Patient } & \multirow[b]{2}{*}{$\begin{array}{l}\text { Day of urine } \\
\text { collection }\end{array}$} & \multicolumn{2}{|c|}{ FIGLU in urine } \\
\hline & & $\begin{array}{l}\mu \mathrm{mol} / \mathrm{mg} \\
\text { creatinine }\end{array}$ & $\mu \mathrm{mol} / 24 \mathrm{hr}$ \\
\hline \multirow{6}{*}{$\begin{array}{l}K S \\
\quad \text { (Male, } 31 \frac{1}{4} \text { yr) }\end{array}$} & 2 before folate ${ }^{1}$ & 16.6 & 3,486 \\
\hline & 1 before folate & 12.4 & 2,373 \\
\hline & 2 during folate & 9.7 & $1,587^{2}$ \\
\hline & 3 during folate & 8.2 & $1,440^{2}$ \\
\hline & 1 after folate & 5.9 & 1,144 \\
\hline & 2 after folate & 4.8 & $872^{2}$ \\
\hline \multirow{6}{*}{$\begin{array}{l}L S \\
\quad \text { (Female, } 8 \mathrm{yr} \text { ) }\end{array}$} & 2 before folinate ${ }^{3}$ & 8.8 & 2,834 \\
\hline & 1 before folinate & 6.9 & $1,803^{2}$ \\
\hline & 2 during folinate & 2.5 & 882 \\
\hline & 3 during folinate & 2.3 & $638^{2}$ \\
\hline & 1 after folinate & 1.7 & 637 \\
\hline & 2 after folinate & 1.9 & 798 \\
\hline
\end{tabular}

${ }^{1}$ Folic acid, $5 \mathrm{mg}$, by mouth every $8 \mathrm{hr}$ for 3 days.

${ }^{2}$ Creatinine content indicated that the 24-hr urine collection was incomplete.

${ }^{3}$ Folinic acid, $6 \mathrm{mg}$ intramuscularly, every $8 \mathrm{hr}$ for 3 days.

loading, approach the degree found in our two patients. It is, therefore, unlikely that our patients suffered a milder degree of glutamate formiminotransferase deficiency than did the five Japanese infants.

FIGLU was not determined in the plasma or CSF of any of the previously studied patients with glutamate formiminotransferase deficiency. Our finding of very small amounts of FIGLU in the plasma of one child, and none in the plasma of
Table 2. Excretion of $N$-formiminoglutamic acid (FIGLU) in urine after histidine loading ${ }^{1}$

\begin{tabular}{lcc} 
& \multicolumn{2}{c}{ FIGLU in urine } \\
\cline { 2 - 3 } \multicolumn{1}{c}{ Subject (sex, age) } & $\mu$ mol/8 hr & Histidine load, \% \\
\hline Mother (female, 30 yr) & 85 & 0.37 \\
Father (male, 38 yr) & 82 & 0.27 \\
Control (female, 28 yr) & 67 & 0.24 \\
Control (female, 42 yr) & 89 & 0.31 \\
Control (male, 58 yr) & 109 & 0.27 \\
\hline
\end{tabular}

${ }^{1}$ Subjects were given a single oral load of histidine, $0.48 \mathrm{mmol} / \mathrm{kg}$.

the other child, suggests that FIGLU is cleared rapidly from the blood by the kidneys. The absence of FIGLU from the CSF of our patients also argues against the likelihood that FIGLU accumulates in the brain in this disorder.

Arakawa and coworkers established the diagnosis of glutamate formiminotransferase deficiency in their five patients $(1-6)$ by assaying in vitro enzyme activity in liver tissue obtained by biopsy or at autopsy. They found enzyme activities varying from $15-50 \%$ of those observed in liver of control subjects. We did not feel ethically justified in obtaining liver biopsies from our patients, in view of the apparently benign nature of their metabolic disorder. The absence of abnormal amounts of FIGLU in the urine of parents of four of the Japanese patients (2-5), as well as in the urine of our patients' parents, together with the appearance of multiple cases within a sibship in one of the Japanese families (5) and in the family of our study, is consistent with an autosomal recessive mode of inheritance for glutamate formiminotransferase deficiency. This also suggests that both the Japanese patients and our two patients were homozygous, rather than 
heterozygous, for the mutant gene which causes glutamate formiminotransferase deficiency. Histidine loading does not appear to be a useful procedure for identifying heterozygotes, inasmuch as the parents of our patients and control subjects excreted similar amounts of FIGLU after histidine loads.

Our two patients do not show any significant impairment of physical growth, and they are not mentally defective. Their development of speech has been delayed, and they have evidence of mild cerebral dysfunction. However, their mother also had delayed speech development, their younger sister has a significantly small head and strabismus, and a maternal aunt is profoundly mentally retarded. Yet none of these relatives excrete FIGLU. Thus, we have reason to doubt that there is any connection between the patients' mild cerebral dysfunction and their metabolic disorder. Our patients also differ from the five Japanese cases (1-6), all of whom were reported to have shown cerebral cortical atrophy and mental retardation. In this respect, it is also noteworthy that the only previously reported Caucasian patient (9) was neurologically normal.

It can be seen (Fig. 4) that glutamate formiminotransferase deficiency is a disorder of histidine catabolism, rather than a disorder of folate metabolism. Since no essential product is formed by the deficient enzymatic reaction, there being many other metabolic pathways leading to glutamic acid, and since the failure to form $N$-formiminotetrahydrofolate should not interfere with other reactions dependent on folic acid derivatives, it is hard to see why this metabolic error should produce any ill effects. The results of analyses of plasma and CSF in our patients suggest that there is probably no appreciable accumulation of FIGLU in tissues.

Thus, it is possible that glutamate formiminotransferase deficiency is a harmless biochemical disorder which, like cystathioninuria (14), type I hyperprolinemia $(8,11)$, and histidinemia (12) produces no characteristic disease syndrome. Excretion of massive amounts of FIGLU in urine could easily go unrecognized unless urines were examined by a paper chromatographic system which employed an ammoniacal solvent. We suspect that in time further patients with this disorder will be discovered, and that some of them will prove to be asymptomatic. It is possible that chronic administration of large doses of folic acid to such patients might reduce or eliminate the urinary excretion of FIGLU, but difficult to see what advantages would accrue from such therapy.

\section{SUMMARY}

We have described two siblings who excrete massive amounts of $N$-formiminoglutamic acid (FIGLU) in their urine. This unusual compound was isolated from urine and rigorously identified as FIGLU by combined gas chromatography-mass spectrometry. Since serum folate levels were normal in our patients, and since they received no drugs that interfere with folate metabolism, it was concluded that the patients probably have a genetically determined deficiency of the hepatic enzyme glutamate formiminotransferase. Unlike children reported previously with this disorder, our patients are not mentally retarded, and they show no symptoms that can be attributed to their metabolic error. Measurement of urinary FIGLU after histidine loading failed to detect the presumed heterozygosity of the parents. Administration of pharmacologic doses of folate to the children decreased their excretion of FIGLU. We conclude that glutamate formiminotransferase deficiency may be a harmless error of histidine catabolism.

\section{REFERENCES AND NOTES}

1. Arakawa, T.: Congenital defects in folate utilization. Amer. J. Med., 48: 594 (1970).

2. Arakawa, T., Ohara, K., Kudo, Z., Tada, K., Hayashi, T., and Mizuno, T.: Hyperfolic-acidemia with formiminoglutamic-aciduria following histidine loading. Tohoku J. Exp. Med., 80: 370 (1963).
3. Arakawa, T., Ohara, K., Takahashi, Y., Ogasawara, J., Hayashi, T., Chiba, R., Wada, Y., Tada, K., Mizuno, T., Okamura, T., and Yoshida, T.: Formiminotransferase-deficiency syndrome: A new inborn error of folic acid metabolism. Ann. Paediat., 205: 1 (1965).

4. Arakawa, T., Tamura, T., Higashi, O,, Ohara, K., Tanno, K., Honda, Y., Narisawa, K., Konno, T., Wada, Y., Sato, Y., and Mizuno, T.: Formiminotransferase deficiency syndrome associated with megaloblastic anemia responsive to pyridoxine or folic acid. Tohoku J. Exp. Med., 94: 3 (1968).

5. Arakawa, T., Tamura, T., Ohara, K., Narisawa, K., Tanno, K., Honda, Y., and Higashi, O.: Familial occurrence of formiminotransferase deficiency syndrome. Tohoku J. Exp. Med., 96: 211 (1968).

6. Arakawa, T., Yoshida, T., Konno, T., and Honda, Y.: Defect of incorporation of glycine-1- ${ }^{14} \mathrm{C}$ into urinary uric acid in formiminotransferase deficiency syndrome. Tohoku J. Exp. Med., 106: 213 (1972).

7. Chanarin, I., Bennett, M. C., and Berry, V.: Urinary excretion of histidine derivatives in megaloblastic anemia and other conditions and a comparison with the folic acid clearance test. J. Clin. Path., 15: 269 (1962).

8. Fontaine, G., Farriaux, J. P., and Dautrevaux, M.: L'hyperprolinémie de type I: Etude d'une observation familiale. Helv. Paediat. Acta, 25: 165 (1970).

9. Herman, R. H., Rosensweig, N. S., Stifel, F. B., and Herman, Y. F. Adult formiminotransferase deficiency: A new entity. Clin. Res., 1 7: 304 (1969).

10. Luhby, A. L., Cooperman, J. M., and Teller, D. N.: Histidine metabolic loading test to distinguish folic acid deficiency from vit. $B_{12}$ in megaloblastic anemias. Proc. Soc. Exp. Biol. Med., 101: 350 (1959).

11. Mollica, F., Pavone, L., and Antener, I.: Pure familial hyperprolinemia: Isolated inborn error of aminoacid metabolism without other anomalies in a Sicilian family. Pediatrics, 48: 225 (1971).

12. Neville, B. G. R., Bentovim, A., Clayton, B., and Shepherd, J.: Histidinaemia. Study of relation between clinical and biological findings in 7 subjects. Arch. Dis. Childhood, 47: 190 (1972).

13. Perry, T. L., Hardwick, D. F., Dixon, G. H., Dolman, C. L., and Hansen, S.: Hypermethioninemia: A metabolic disorder associated with cirrhosis, islet cell hyperplasia, and renal tubular degeneration. Pediatrics, 36: 236 (1965).

14. Perry, T. L., Hardwick, D. F., Hansen, S., Love, D. L., and Israels, S.: Cystathioninuria in two healthy siblings. New Engl. J. Med., 278: 590 (1968)

15. Perry, T. L., Shaw, K. N. F., Walker, D., and Redlich, D.: Urinary excretion of amines in normal children. Pediatrics, 30: 576 (1962).

16. Perry, T. L., Stedman, D., and Hansen, S.: A versatile lithium buffer elution system for single column automatic amino acid chromatography. J. Chromatogr. 38: 460 (1968).

17. Rothenberg, S. P., DaCosta, M., and Rosenberg, Z.: A radioassay for serum folate: Use of a two-phase sequential-incubation, ligand-binding system. New Engl. J. Med., 286: 1335 (1972).

18. Tabor, H., and Wyngarden, L.: A method for the determination of formiminoglutamic acid in urine. J. Clin. Invest., 37: 824 (1958).

19. Tabor, H., and Wyngarden, L.: The enzymatic formation of formiminotetrahydrofolic acid, 5,10-methenyltetrahydrofolic acid, and 10-formyltetrahydrofolic acid in the metabolism of formiminoglutamic acid. J. Biol. Chem., 234: 1830 (1959).

20. Tibbling, G.: A method for determination of vitamin $B_{12}$ in serum by radioassay. Clin. Chim. Acta, 23: 209 (1969).

21. Waxman, S., Schreiber, C., and Herbert, V.: Radioisotopic assay for the measurement of serum folate levels. Blood, 38: 219 (1971).

22. Wilmanns, W., and Burgmann, T.: Die Bestimmung der Formiminoglutaminsäureausscheidung als Funktionstest bei Folsäure-und Vitamin-B -Stoffwechselstörungen. Deut. Med. Wosch., 93. $1801(1968)$.

23. Zalusky, R., and Herbert, V.: Urinary formiminoglutamic acid as test of tolic-acid deficiency. Lancet, $i: 108$ (1962).

24. Technicon Instruments Corporation, Tarry town, N. Y.

25. Sigma Chemical Company, St. Louis, Mo.

26. Gilson Medical Electronics, Middleton, Wisc.

27. Varian MAT, Bremen, Germany.

28. Applied Science Laboratories, Inc., State College, Pa.

29. Fluka, A. G., Buchs, Switzerland.

30. L-Histidine hydrochloride monohydrate, A grade, obtained from Calbiochem, San Diego, Calif.

31. Spinco Division, Beckman Instruments, Palo Alto, Calif.

32. Informed consent was obtained from all subjects and parents of minor subjects in this study.

33. We thank Dr. Henry G. Dunn for expert technical assistance and clinical advice regarding the patients.

34. This research was supported by a grant from the Medical Research Council of Canada.

35. Requests for reprints should be addressed to: T. L. Perry, M.D., Department of Pharmacology, University of British Columbia, Vancouver, V6T 1W5, British Columbia (Canada).

36. Accepted for publication October 31, 1974. 